American Journal of Pharmacology and Toxicology 5 (2): 58-64, 2010

ISSN 1557-4962

(C) 2010 Science Publications

\title{
Safety and Efficacy of an Ayurvedic Formulation Cystone in Management of Ureteric Calculi: A Prospective Randomized Placebo Controlled Study
}

\author{
${ }^{1}$ N.K. Mohanty, ${ }^{1}$ R.L. Nayak and ${ }^{2}$ Pralhad S. Patki \\ ${ }^{1}$ Department of Urology, Safdarjung Hospital, New Delhi, India \\ ${ }^{2}$ Department of Clinical Pharmacology, R\&D Center, \\ The Himalaya Drug Company, Bangalore, India
}

\begin{abstract}
Problem statement: Medical management of urolithiasis is still a challenge for modern medical practice. In the present study, Cystone tablet, an Ayurvedic formulation claimed to be useful in urolithiasis was evaluated for its safety and efficacy in reduction or expulsion of ureteric calculi and to assess the role of Cystone in relieving the clinical symptoms. Approach: This was a prospective randomized, double blind placebo-controlled trial amongst 52 patients with upper urinary tract calculi of 5-10 mm diameter. Patients were evaluated by plain abdominal film of the Kidneys, Ureter and Bladder (KUB) plus an ultrasound examination, for 6 months. Patients were equally divided into active treatment or placebo. The patients were advised to take Cystone or placebo in a dose of one tablet, thrice daily for 6 months. Patients kept a record of number of pain episodes; severity of pain was assessed by Visual Analogue Scale (VAS). In addition, other parameters such as fever, low backache and decrease in frequency of urine were evaluated to assess the relief of clinical symptoms. Urinary microscopy and hamatological parameters were also evaluated. Results: In active medication group, there was a significant reduction in the size of the calculi while there was an increase in the placebo arm. There was significant lower VAS score in the active medication arm as compared to placebo. On urine analysis, significant reduction in microscopic hematuria, pus cells (pyuria), bacteruia and crystalline sediments was seen. Significant disappearance of the calculi by both X-ray abdomen and ultrasonography and a significant reduction in the size of the stone was seen with Cystone treatment. There was no improvement in relief of clinical symptoms or investigations in the placebo treated subjects. Conclusion: This study suggested that the Ayurvedic formulation Cystone tablet had a therapeutic promise in the management of ureteric calculi. It probably helped in reducing the size of the calculi and facilitates in its passage and significantly relieves the symptoms with improvement in urine parameters. This formulation was well tolerated.
\end{abstract}

Key words: Urolithiasis, ayurvedic formulation, cystone

\section{INTRODUCTION}

Humankind is known to be suffering from urinary stone disease, which was first noticed by Egyptian mummies dated to $4800 \mathrm{BCE}^{1}$. Hippocrates in the 4 th century BCE noted renal stones together with a renal abscess and wrote in the Hippocratic oath "I will not cut the stone" (Clendening, 1960). Urolithiasis in its different forms is a frequently encountered urological condition. For many years it has been at the forefront of urology. This situation might have changed with the advent of new, less invasive approaches to the management of urinary calculi. Nevertheless, urinary stones continue to occupy an important place in everyday urological practice. Currently urinary stones affect $10-12 \%$ of the population with a peak incidence at 20-40 years of age (Wasserstein, 1998). It is one of the most common and painful urologic disorder of the urinary tract that affects more than 3 million people every year alone in the United States (Hollingsworth et al., 2006). The lifetime risk of developing urolithiasis ranges between 5 and $12 \%$ (Alok et al., 2008) and significantly affects the economy and public health as it has a high rate of recurrence (Hiatt et al., 1982).

Risk factors for developing urolithiasis include age, sex, diet, geographic location, genetic predisposition and urinary composition. Apart from these, the anatomy

Corresponding Author: Pralhad S. Patki, Department of Clinical Pharmacology, R\&D Center, The Himalaya Drug Company, Makali, Bangalore-562 123 India Tel: +91 8023714444 
Am. J. Pharm. \& Toxicol., 5 (2): 58-64, 2010

of the upper and the lower tract might be contributing factor in predisposing an individual to urinary tract infection or stasis (Gupta and Kesarwani, 2002). Small urinary calculi pass out of the body without any clinical intervention (Miller and Kane, 1999). In several studies, it has been reported that spontaneous passage rates of urinary stones ranges between $70-98 \%$ for small $(\leq 5 \mathrm{~mm})$ distal ureteric calculi (Healy and Ogan, 2005). However size and location of the calculi play an important role in predicting spontaneous passage. Typical symptoms of acute renal colic are intermittent colicky flank pain that may radiate to the lower abdomen or groin, often associated with nausea and vomiting (Eskelinen et al., 1998). Lower urinary tract symptoms such as dysuria, urgency and frequency may occur as the stone enters the ureter. Large calculi associated with unbearable pain can be treated with ureteroscopy, extracorporeal shock wave lithotripsy, percutaneous nephrostomy and surgery. Calcium channel blockers and adrenergic alpha antagonists and steroids are effective in enhancing the passage of urinary calculi. Phytotherapy with medicinal plants is widely used worldwide as an alternative primary healthcare. Regarding the treatment of urinary stone disease, several medicinal plants are available (Nirdnoy and Muangman, 1991; Yasui et al., 1999; Selvam et al., 2001; Premgamone et al., 2001; Freitas et al., 2002; Atmani et al., 2004). Since the plants are claimed to be non-toxic, low-cost, available in rural areas and culturally acceptable, their effectiveness in the treatment of urinary stones has been widely studied. Herbal medicines have been used to help in urolithiasis through anti-inflammatory, diuretic, litholytic, antimicrobial and antispasmodic actions, though many of these properties are speculative. Cystone tablets, one such an Ayurvedic formulation and has been claimed for its safety and efficacy in Urolithiasis. The principal herbs of Cystone tablets (Table 1) have undergone extensive studies and geographical source and harvest time for each of the herbal ingredients have been recorded. Good Agricultural and Collection Practice (GACP) was followed during the collection and manufacture of this Ayuurvedic formulation (Sing et al., 2007. Botanical identification and an Ayurvedic criteria for desired quality were in accordance with the guidelines of Pharmacopoeial Standards of an Ayurvedic formulations (Fong, 2002) and were carried out by a qualified chemist approved by the Food and Drug Administration. This formulation has been approved by regulatory authorities in India as an Ayurvedic formulation and is available for clinical practice for the past sixty years. This study was aimed to evaluate the efficacy and safety of Cystone tablets in subjects with urolithiasis.
Table 1: Principal herbs in Cystone tablet

\begin{tabular}{lc}
\hline Ingredients & Quantity $(\mathrm{mg})$ \\
\hline Didymocarpus pedicellata & 130 \\
Saxifraga ligulata & 98 \\
Rubia cordifolia & 32 \\
Cyperus scariosus & 32 \\
Achyranthes aspera & 32 \\
Onosma bracteatum & 32 \\
Vernonia cinerea & 32 \\
Shilajeet (Purified) & 26 \\
Hajrul yahood bhasma & 32 \\
\hline
\end{tabular}

\section{MATERIALS AND METHODS}

Study design: This was a randomized placebo-controlled double blind clinical trial carried out at the Department of Urology, Safdarjung Hospital, New Delhi, India between January 2008 and March 2009 in accordance to the ethical guidelines of Helsinki (Puri et al., 2009). Allocation was concealed. The sample size of 52, with 26 in each arm was calculated to have a power to detect a $25 \%$ reduction with urinary stones at $95 \%$ confidence limit.

Inclusion and exclusion criteria: Patients of either sex aged 18-65 years presenting clinically with characteristic loin pain, vomiting, fever and radiological or ultrasonographically diagnosed with ureteric calculi measuring between 5-10 $\mathrm{mm}$ in size and willing to sign the informed consent form and comply with the study procedures were included in the study. Those with larger urinary calculi, renal and or hepatic pathology and any systemic disorder requiring other medication or surgery were excluded from the study. Pregnant and lactating women were not included in the study.

Study procedure: This study was carried out in 52 consecutive eligible patients out of 81 patients who attended the Urology Clinic at Safdarjung Hospital, New Delhi, India. The study protocol, Case Report Forms (CRF), regulatory clearance documents, product related information and informed consent forms (in English and Hindi) were approved by the institutional ethics committee. The patients were informed about the study drug, its effects, duration of the trial and overall plan of the study and were included in the clinical study only after written informed consent was obtained from each of them. They were free to withdraw from the study if they so desired. Patients ate their ad libitum diets. Detailed clinical history was noted by interviewing the patients. Thorough clinical examination and symptomatic evaluation was carried out and the details were noted in the CRF. Urolithiasis was determined clinically, the diagnosis was confirmed by plain X-Ray of the abdomen followed by 
ultrasonography. The X-Ray KUB and ultrasonography was used to calculate the surface area of each stone based on length and width. Largest diameter of a stone was considered instead of the surface area in ultrasonography evaluation. The cumulative diameter was calculated for subjects with multiple calculi. Patients were advised to take the Ayurvedic formulation Cystone or an identical placebo in a dose of one tablet thrice daily orally for six months. All patients were asked to maintain a record of number of pain episodes, while severity of pain was assessed on a visual analogue scale (Hollingsworth et al., 2006). Patients underwent clinical, hematological and radiological evaluation on entry, at 3 and 6 months. The clinical symptoms like fever and low backache were scored using numerical scale. They were allowed Diclofenac $50 \mathrm{mg}$ tablet in case of severe abdominal pain.

Primary and secondary outcome measures: The predefined primary outcome measures were the effect on change in the number and size, spontaneous passage of stone and symptomatic relief. The predefined secondary outcome was incidence of adverse effects and patient compliance.

Adverse events: All adverse events reported or observed by patients were recorded with information about severity, date of onset, duration and action taken regarding the study drug. Relation of adverse events to study medication were predefined as "Unrelated" (a reaction that does not follow a reasonable temporal sequence from the administration of the drug), "Possible" (follows a known response pattern to the suspected drug, but could have been produced by the patient's clinical state or other modes of therapy administered to the patient) and "Probable" (follows a known response pattern to the suspected drug that could not be reasonably explained by the known characteristics of the patient's clinical state).

Patients were allowed to voluntarily withdraw from the study, if they had experienced serious discomfort during the study or sustained serious clinical events requiring specific treatment. For patients withdrawing from the study, efforts were made to ascertain the reason for dropout. Non-compliance (defined as failure to take less than $80 \%$ of the medication) was not regarded as treatment failure and reasons for noncompliance were noted.

Statistical analysis: Statistical analysis was carried out using Fisher's Exact Test for presence or absence of various signs and symptoms. Repeated measures of
ANOVA followed by Dunnett's Multiple Comparison Posthoc Test were used for analysis of haematological parameters. Pyuria was analyzed by repeated measures of ANOVA using Friedman test followed by Dunnett's Multiple Comparison Posthoc Test. Calculi size before and after treatment was analyzed using Paired Student's ' $\mathrm{t}$ ' test. Values are expressed as mean $\pm \mathrm{SD}$ for haematological parameters, pyuria and calculi size and remaining parameters were evaluated by the incidence of symptoms. The minimum level of significance was fixed at $\mathrm{p}<0.05$. Statistical analysis was carried out using GraphPad Prism Version 4.03 for Windows, GraphPad Prism Software, San Diego California USA.

\section{RESULTS}

The demographic data of the patients on entry (Table 2) indicated that thirty eight males and fourteen female patients with a mean age of $34.73 \pm 10.09$ years were included in the study. Out of the 52 subjects, 26 subjects each received either Cystone tablets or placebo in a random fashion. With Cystone treatment, a significant $(\mathrm{p}<0.0001)$ symptomatic relief from intermittent abdominal pain (58\%), fever (92\%), low backache $(54 \%)$ was observed (Table 3 ).

There was also an improvement in the frequency and flow of urine though it was not significant. Urine analysis, indicated significant $(\mathrm{p}<0.0001)$ improvement in microscopic hematuria, pus cells, bacteriruria and crystalline sediments (Table 4).

Disappearance of the calculi as seen by ultrasonography was noticed in 13 out of 26 patients $(50 \%)$ treated with Cystone tablets $(\mathrm{p}<0.0001)$ and a decrease in the size of the stone in remaining subjects. In patients treated with placebo out of 26 patients, there was disappearance of stone in 2 patients. Disappearance of the calculi by plain X-ray abdomen and pelvis was seen in 15 patients out of 26 patients $(58 \%)$ treated with Cystone tablets $(\mathrm{p}<0.0001)$ there was decrease in the size of the stone in another 11 subjects. In patients treated with placebo out of 26 patients, there was disappearance of stone in 2 patients (Table 5).

\begin{tabular}{lll}
\multicolumn{2}{l}{ Table 2: Demographic data on patients on entry } \\
\hline Parameters & Cystone & Placebo \\
\hline Mean age in years & $34.00 \pm 10.09$ & $34.00 \pm 8.60$ \\
Male: Female & $20: 6$ & $18: 8$ \\
Smokers & 12 & 16 \\
Alcoholics & 10 & 12 \\
Diet (Veg: Nonveg) & $14: 12$ & $20: 6$ \\
No. of sedentary workers & 20 & 22 \\
Previous history of constipation & 16 & 18 \\
Pain & 26 & 26 \\
Low back ache & 26 & 24 \\
Fever with rigors & 13 & 14 \\
\hline
\end{tabular}


Am. J. Pharm. \& Toxicol., 5 (2): 58-64, 2010

Table 3: Effect of drug therapy on clinical symptoms of urolithiasis

\begin{tabular}{|c|c|c|c|c|c|c|c|}
\hline \multirow[b]{2}{*}{ Parameters } & & \multicolumn{3}{|c|}{ Cystone $(\mathrm{n}=26)$} & \multicolumn{3}{|c|}{ Placebo $(\mathrm{n}=26)$} \\
\hline & & On entry & $\begin{array}{l}\text { End of } \\
\text { 3rd month }\end{array}$ & $\begin{array}{l}\text { End of } \\
6 \text { th month }\end{array}$ & On entry & $\begin{array}{l}\text { End of } \\
\text { 3rd month }\end{array}$ & $\begin{array}{l}\text { End of } \\
\text { 6th month }\end{array}$ \\
\hline \multirow[t]{2}{*}{ Pain } & Present & 26 & 23 & 11 & 26 & 20 & 19 \\
\hline & Absent & 0 & 3 & $15^{\mathrm{a}, \mathrm{b}}$ & 0 & 6 & 7 \\
\hline \multirow[t]{2}{*}{ Fever } & Present & 13 & 4 & 0 & 14 & 8 & 8 \\
\hline & Absent & 13 & $22^{\mathrm{c}}$ & $26^{\mathrm{a}}$ & 12 & 18 & 18 \\
\hline \multirow[t]{2}{*}{ Low back ache } & Present & 26 & 19 & 12 & 24 & 24 & 22 \\
\hline & Absent & 0 & $7^{\mathrm{d}}$ & $14^{\mathrm{a}}$ & 2 & 2 & 4 \\
\hline \multirow[t]{2}{*}{ Decrease in urinary frequency } & Present & 8 & 4 & 5 & 3 & 3 & 3 \\
\hline & Absent & 18 & 22 & 21 & 23 & 23 & 23 \\
\hline
\end{tabular}

p-value: ${ }^{a}: \mathrm{p}<0.0001$ as compared to 'on entry' value; ${ }^{b}: \mathrm{p}<0.01$ as compared to '3rd month' value; ${ }^{\mathrm{c}}: \mathrm{p}<0.017$ as compared to 'on entry' value; ${ }^{\text {; }}$ $\mathrm{p}<0.001$ as compared to 'on entry' value

Table 4: Effect of drug therapy on urine analysis

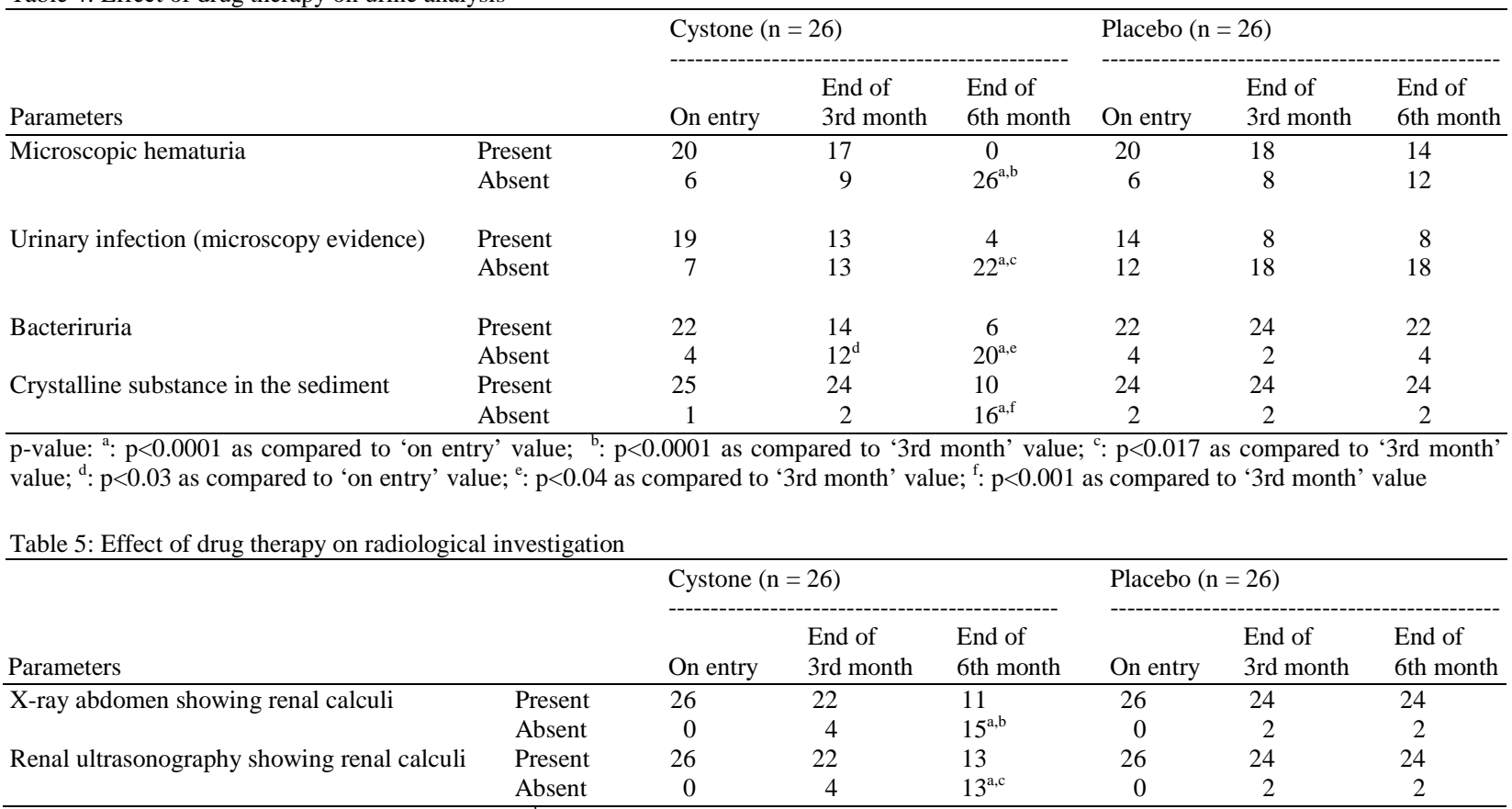

p-value: ': $\mathrm{p}<0.0001$ as compared to 'on entry' value; ' $\mathrm{p}<0.0002$ as compared to ‘3rd month' value; ${ }^{\mathrm{c}}$ : $\mathrm{p}<0.017$ as compared to ‘3rd month' value

Table 6: Effect of the drug on pyuria

\begin{tabular}{|c|c|c|c|c|c|c|}
\hline \multirow[b]{2}{*}{ Parameter } & \multicolumn{3}{|c|}{ Cystone $(\mathrm{n}=26)$} & \multicolumn{3}{|c|}{ Placebo $(n=26)$} \\
\hline & On entry & End of $3^{\text {rd }}$ month & End of $6^{\text {th }}$ month & On entry & End of $3^{\text {rd }}$ month & End of $6^{\text {th }}$ month \\
\hline Pyuria & $1.39 \pm 0.85$ & $0.58 \pm 0.70^{\mathrm{a}}$ & $0.12 \pm 0.33^{\mathrm{b}}$ & $1.44 \pm 1.2$ & $1.23 \pm 2.4$ & $1.06 \pm 1.8$ \\
\hline \multicolumn{7}{|c|}{$\begin{array}{l}\text { p-value: }{ }^{\text {a }}: \mathrm{p}<0.01 \text { as compared to 'on entry' value; }{ }^{\mathrm{b}}: \mathrm{p}<0.001 \text { as compared to '3rd month' value. The values for Pyuria is evaluated using } 4 \text { point } \\
\text { scale: Occasional to Nil: } 0 ; 1: \leq 5 ; 2: 6-9 ; 3: \geq 10\end{array}$} \\
\hline & & On entry & & & End of 6th month & \\
\hline \multicolumn{2}{|c|}{ Parameter } & Cystone $(\mathrm{n}=26)$ & Placebo $(n=26)$ & & Cystone $(\mathrm{n}=26)$ & Placebo $(n=26)$ \\
\hline \multicolumn{2}{|c|}{ Calculi size in $\mathrm{mm}$} & $10.56 \pm 3.28$ & $10.22 \pm 4.1$ & & $4.51 \pm 6.30^{\mathrm{a}}$ & $11.28 \pm 6.1$ \\
\hline
\end{tabular}

There was significant $(\mathrm{p}<0.001)$ reduction in the pus cells (pyuria) at the end of treatment in Cystone group (Table 6) .The study showed significant reduction in the calculi size from $10.56 \pm 3.28-4.51 \pm 6.30 \mathrm{~mm}(57 \%)$ at the end of the treatment in Cystone group $(\mathrm{p}<0.0001)$ as compared to placebo (increase by $10.37 \%$ ) (Table 7). 
Am. J. Pharm. \& Toxicol., 5 (2): 58-64, 2010

Table 8: Effect of drug on various haematological parameters

\begin{tabular}{|c|c|c|c|c|c|c|}
\hline \multirow[b]{2}{*}{ Parameter } & \multicolumn{3}{|l|}{ Cystone } & \multicolumn{3}{|l|}{ Placebo } \\
\hline & On entry & $\begin{array}{l}\text { End of } \\
\text { 3rd month }\end{array}$ & $\begin{array}{l}\text { End of } \\
\text { 6th month }\end{array}$ & On entry & $\begin{array}{l}\text { End of } \\
\text { 3rd month }\end{array}$ & $\begin{array}{l}\text { End of } \\
\text { 6th month }\end{array}$ \\
\hline Hemoglobin $\left(\mathrm{g} \mathrm{dL}^{-1}\right)$ & $11.84 \pm 1.18$ & $11.82 \pm 1.20$ & $11.93 \pm 1.67$ & $12.44 \pm 2.36$ & $11.23 \pm 2.89$ & $12.92 \pm 3.41$ \\
\hline WBC (/cu.mm.) & $7438.00 \pm 1552$ & $7562.00 \pm 655$ & $7365.00 \pm 582$ & $8890.00 \pm 1864$ & $8667.00 \pm 1456$ & $8552.0 \pm 1224$ \\
\hline Polymorphs (\%) & $62.73 \pm 6.08$ & $62.38 \pm 4.01$ & $62.04 \pm 3.63$ & $64.84 \pm 9.67$ & $69.84 \pm 10.54$ & $66.45 \pm 9.12$ \\
\hline Lymphocytes (\%) & $33.62 \pm 5.93$ & $34.15 \pm 4.73$ & $34.00 \pm 3.81$ & $38.68 \pm 7.26$ & $38.67 \pm 8.18$ & $37.26 \pm 7.99$ \\
\hline Eosinophils (\%) & $2.35 \pm 2.00$ & $2.85 \pm 1.43$ & $2.85 \pm 1.29$ & $2.78 \pm 1.20$ & $2.23 \pm 1.54$ & $2.54 \pm 2.61$ \\
\hline Monocytes (\%) & $1.00 \pm 2.00$ & $1.00 \pm 1.10$ & $1.12 \pm 1.56$ & $1.22 \pm 1.86$ & $1.59 \pm 1.99$ & $1.34 \pm 1.57$ \\
\hline $\operatorname{ESR}(\mathrm{mm})$ & $22.88 \pm 11.27$ & $19.62 \pm 8.88^{\mathrm{a}}$ & $18.19 \pm 9.19^{\mathrm{a}}$ & $20.45 \pm 13.38$ & $21.09 \pm 12.16$ & $22.52 \pm 10.88$ \\
\hline
\end{tabular}

p-value: ${ }^{a}$ : $p<0.001$ as compared to 'on entry' value

There were no changes in haematological parameters except for a significant decrease in ESR (Table 8). There were no adverse effects either reported or observed during the study.

\section{DISCUSSION}

There are a number of options for treatment of urinary calculi, including surgery, endoscopic procedures such as ureteroscopy, percutaneous nephrolithiotomy and extracorporeal shockwave lithotripsy (Heilberg and Schor, 2006). Patients invariably prefer a medical therapy for the advantage of convenience. Medications like calcium channel blockers, alpha-adrenergic blockers, steroids are used but adverse effects compromise their long-term consumption. On the other hand, some herbal remedies have been used to treat urinary stone disease, although scientific principles have been lacking. With the understanding of many pathophysiological features underlying urinary stone disease and the mechanism of herbal remedies that can have a role in the formation and treatment of urinary stones; phytotherapy might be an alternative treatment with an effective, safe and acceptable options. Although some oral medications have positive effects, they are not effective in all patients. Oral citrate is one of the most widely used medical therapies for preventing urinary stone disease (Serhat and Kupeli, 2006). However, this drug is not tolerated by all patients and some patients are still active stone formers during this therapy (Mattle and Hess, 2005). Due to the adverse effects of these drugs, alternative treatment modalities composed of herbal remedies have been the mainstay of medical therapy for thousands of years, especially in Eastern civilizations (Serhat and Kupeli, 2006). Use of medicinal plants as a source of relief and cure from various illness is as old as humankind itself. Even today, medicinal plants provide a cheap source of drugs for majority of world's population. Plants have provided and will continue to provide not only directly usable drugs, but also a great variety of chemical compounds that can be used as starting points for the synthesis of new drugs with improved pharmacological properties (Potterat and Hostettmann, 1995). World Health Organization has also emphasized development and utilization of herbal drugs and traditional medicines for the benefit of the world population, in terms of cost effectiveness and side effects of the drugs. The organization has also estimated that about $80 \%$ of the population living in the developing countries relies on traditional medicine for their healthcare needs (World Health Organization, 2002).

Cystone is an Ayurvedic formulation, designed and developed for the management of urolithiasis or renal calculi. This product came into existence in 1943 and since then this product has been in use all over the world for the management of urolithiasis and UTI.

Herbs like Didymocarpus pedicellata has been shown to have diuretic activity (Chopra et al., 1996a). Another plant, Saxifraga ligulata, is reported to have active principles like afzelechin and bergenin. Afzelechin and bergenin are tannins and possess astringent properties, which make them effective antimicrobial agents. Bergenin is a known diuretic and is helpful in dissolving kidney stones (Asolkar et al., 1992; Chopra et al., 1996b). The roots of Rubia cordifolia contain ruberythic acid, which has been proved to dissolve oxalate stones present in the urinary tract, thereby facilitating their expulsion without recourse to surgery (Basu and Hazra, 2006; Tripathi and Sharma, 1999; Jisha and Nair, 2008). It also possesses astringent, antibacterial and anti-inflammatory actions. The oil from the roots of Cyperus scariosus has been found to exhibit anti-inflammatory properties (Khare, 2004; Chopra et al., 1996c). Studies conducted on the extracts of Cyperus scariosus were found to have potent antioxidant activity. Achyranthes aspera has potent anti-inflammatory, astringent, demulcent and diuretic activity (Chopra et al., 1996d). Onosma bracteatum is known to have diuretic action. It regulates urine output, acts as a demulcent and provides soothing action. It is useful in bladder irritation and is a spasmolytic (Khare, 2007). Hajrul Yahood bhasma is 
useful as a diuretic and a lithotropic. It is given in retention of urine and in other diseases of the urinary tract. Shilajeet (purified) treats urinary disorders due to its tonic activity (Agarwal et al., 2007). It is probable that these ingredients may be producing an additive activity to bring about relief in Urolithiasis. Several of these herbs contain saponins which have antiuroliathiatic effect.

\section{CONCLUSION}

The present study indicates that Cystone tablet is an effective and safe alternate in the management of Urolithiasis. It brings about significant symptomatic relief and helps in expulsion of stones or reducing the size of the renal stones. No clinically significant adverse reactions were reported or observed during the study period. A further study in a larger population will be required to confirm the evidence seen in the present clinical study.

\section{ACKNOWLEDGEMENT}

Thanks to The Himalaya Drug Company for supply of study medications and facilities.

\section{REFERENCES}

Asolkar, L.V., K.K. Kakkar and O.J. Chakre, 1992. Saxifraga Ligulata, Glossary of Indian Medicinal plants with Active Principles. 2nd Edn., CSIR Publication, New Delhi, ISBN: 81-7236-048-7, pp: 122.

Atmani, F., Y. Slimani, M. Mimouni, M. Aziz and B. Hacht et al., 2004. Effect of aqueous extract from Herniaria hirsuta L. on experimentally nephrolithiasic rats J. Ethnopharmacol., 95: 87-93. PMID: 15374612

Basu, S. and B.B. Hazra, 2006. Evaluation of nitric oxide scavenging activity, in vitro and ex vivo, of selected medicinal plants traditionally used in inflammatory diseases. Phytother. Res., 20: 896-900. PMID: 16909442

Agarwal, S.P., R. Khanna, R. Karmarkar, M.K. Anwer and R.K. Khar, 2007. Shilajit: A review. Phytother. Res., 21: 401-405. PMID: 17295385

Alok, S., M. Sabharwal, S. Rawal and A. Mohor, 2008. Herbal drugs in antilithiasis-A review. Int. J. Pharma. Res. Dev., 1: 1-7.

Chopra, R.N., S.L. Nayar and L.C. Chopra, 1996a. Didymocarpus Pedicellata, Glossary of Indian Medicinal Plants. 4th Edn., National Institute of Science Communication, New Delhi, ISBN: 817236-126-2, pp: 96.
Chopra, R.N., S.L. Nayar and L.C. Chopra, 1996b. Saxifraga Ligulata, Glossary of Indian Medicinal Plants. 4th Edn., National Institute of Science Communication, New Delhi, ISBN: 81-7236-1262, pp: 223.

Chopra, R.N., S.L. Nayar and L.C. Chopra, 1996 c. Cyperus Scariosus, Glossary of Indian Medicinal Plants. 4th Edn., National Institute of Science Communication, New Delhi, ISBN: 81-7236-1262, pp: 89.

Chopra, R.N., S.L. Nayar and L.C. Chopra, 1996d. Achyranthes Aspera, Glossary of Indian Medicinal Plants. National Institute of Science Communication, New Delhi, ISBN: 81-7236-1262, pp: 4.

Clendening, L., 1960. Source Book of Medical History. Dove Publication, New York, ISBN: 13: 9780486206219, pp: 685.

Eskelinen, M., J. Ikonen and P. Lipponen, 1998. Usefulness of history-taking, physical examination and diagnostic scoring in acute renal colic. Eur. Urol., 34: 467-473. PMID: 9831787

Fong, H.H., 2002. Integration of herbal medicine into modern medical practices: Issues and prospects. Integr. Cancer Ther., 1: 287-293. PMID: 1467286

Freitas, A.M., N. Schor and M.A. Boim, 2002. The effect of Phyllanthus niruri on urinary inhibitors of calcium oxalate crystallization and other factors associated with renal stone formation. BJU Int., 89: 829-834. PMID: 12010223

Gupta, N.P. and P. Kesarwani, 2002. Current approaches in the medical management of Urolithiasis: A review article. Indian J. Urol., 19: 20-24.

http://www.indianjurol.com/text.asp?2002/19/1/20/ 20287

Healy, K.A. and K. Ogan, 2005. Non surgical management of Urolithiasis: An overview of expulsive therapy. J. Endourol., 19: 759-767. PMID: 16190824

Hiatt, R.A., L.G. Dales, G.D. Friedman and E.M. Hunkeler, 1982. Frequency of Urolithiasis in a prepaid medical care program. Am. J. Epidemiol., 115: 255-265. PMID: 7058784

Hollingsworth, J.M., M.A. Rogers, S.R. Kaufman, T.J. Bradford and S. Saint et al., 2006. Medical therapy to facilitate urinary stone passage: A metaanalysis. Lancet, 368: 1171-1179. PMID: 17011944

Heilberg, I.P. and N. Schor, 2006. Renal stone disease: Causes, evaluation and medical treatment. Arq. Bras. Endocrinol. Metab., 50: 823-833. PMID: 17117307 
Jisha, J. and C.K. Nair, 2008. Amelioration of cisplatininduced nephrotoxicity in Swiss albino mice by Rubia cordifolia extract. J. Cancer Res. Ther., 4: 111-115. PMID: 18923202

Khare, C.P., 2004. Indian Medicinal Plants: An Illustrated Dictionary. Springer-Verlag Berlin, Heidelberg, ISBN: 978-0-387-70637-5, pp: 900.

Khare, C.P., 2007. Encyclopedia of Indian Medicinal Plants. Springer, ISBN: 3-540-20033-9, pp: 337-338.

Mattle, D. and B. Hess, 2005. Preventive treatment of nephrolithiasis with alkali citrate: A critical review. Urol. Res., 33: 73. PMID: 15875173

Miller, O.F. and C.J. Kane, 1999. Time to stone passage for observed ureteral calculi: A guide for patient education. J. Urol., 162: 688-690. PMID: 10458343

Nirdnoy, M. and V. Muangman, 1991. Effects of Folia orthosiphonis on urinary stone promoters and inhibitors. J. Med. Assoc. Thai., 74: 318-321. PMID: 1744535

Potterat, O. and K. Hostettmann, 1995. Plant Sources of Natural Drugs and Compounds. In: Encyclopedia of Environmental Biology, Nierenberg, W.A. (Ed.). Academic Press Inc., London, ISBN: 13: 9780122267307, pp: 139-153.

Premgamone, A., P. Sriboonlue, W. Disatapornjaroen, S. Maskasem and N. Sinsupan et al., 2001. A long-term study on the efficacy of a herbal plant, Orthosiphon grandiflorus and sodium potassium citrate in renal calculi treatment. Southeast Asian J. Trop. Med. Public Health, 32: 654-660. PMID: 11944733

Puri, K.S., K.R. Suresh, N.J. Gogtay and U.M. Thatte, 2009. Declaration of Helsinki, 2008: Implications for stakeholders in research. Postgrad. Med., 55: 131-134. PMID: 19550060
Selvam, R., P. Kalaiselvi, A. Govindaraj, V.B. Murugan and A.S. Sathish Kumar, 2001. Effect of a lanata leaf extract and Vediuppu chunnam on the urinary risk factors of calcium oxalate urolithiasis during experimental hyperoxaluria. Pharmacol. Res., 43: 89-93. PMID: 11207071

Serhat, G. and B. Kupeli, 2006. Consumption of historical and current phytotherapeutic agents for urolithiasis: A critical review. J. Urol., 176: 450-455. PMID: 16813863

Sing, B.B., S.P. Vinjamury, C.D. Martirosian, E. Kubik and L.C. Mishra et al., 2007. Ayurvedic and collateral herbal treatments for hyperlipidemia: A systematic review of randomized controlled trials and quasi-experimental designs. Altern. Ther. Health Med., 13: 22-28. PMID: 17658119

Tripathi, Y.B and M.M. Sharma, 1999. The interaction of Rubia cordifolia with iron redox status: A mechanistic aspect in free radical reactions. Phytomedicine, 6: 51-57. PMID: 10228612

Wasserstein, A.G., 1998. Nephrolithiasis: Acute management and prevention. Dis. Mon., 44: 196-213. PMID: 9656969

World Health Organization, (WHO), 2002. World Health Organization monographs on selected medicinal plants. World Health Organization, Geneva.

Yasui, T., K. Fujita, M. Sato, M. Sugimoto and M. Iguchi et al., 1999. The effect of takusha, a kampo medicine, on renal stone formation and osteopontin expression in a rat urolithiasis model. Urol. Res., 27: 194-199. PMID: 10422821 